\title{
LA RECEPCIÓN DEL ESTILO FRANCÉS EN LOS TRATADOS DE DANZA ESPAÑOLES DEL SIGLO XVIII
}

\section{The Reception of the French Style in Treatises on Spanish Dance in the $18^{\text {th }}$ Century}

\author{
Pilar MONTOYA \\ Universidad Autónoma de Madrid \\ pilarmon63@hotmail.com
}

Fecha de recepción: 23/06/2015

Fecha de aceptación definitiva: 11/11/2015

RESUMEN: El proceso de aceleración que sufrió el «afrancesamiento» de la cultura española bajo el reinado de Felipe V inauguró una nueva era en la sociedad de nuestro país. Esta cuestión, tratada desde diversas perspectivas por investigadores franceses y españoles, responde a un complejo fenómeno en el que múltiples aspectos han de ser analizados.

La danza, arte plenamente integrado en la estructura cortesana, no es ajena a este influjo. Sin embargo la preponderancia del estilo francés se vio obligada a convivir con la fuerte presencia de la cultura italiana y la consecuente reacción del país autóctono. A pesar de todo, el «danzar a la francesa» siguió practicándose asiduamente y fue la principal referencia a la que aluden sin excepción todos los maestros españoles a lo largo del siglo.

Palabras clave: España; Francia; danza; siglo XVIII; recepción, corte.

ABSTRACT: The acceleration of French influence on Spanish culture that took place under the reign of Felipe $\mathrm{V}$ inaugurated a new era in Spanish society. This question is addressed from different perspectives by French and Spanish researchers and it reflects a complex phenomenon in which multiple aspects have to be analyzed. 
Dance, an art form fully integrated into the court structure, was no stranger to this influence. But the preponderance of French style was forced to live with the strong presence of Italian culture and the consequent reaction of native Spaniards. Nevertheless, the "French dance» was practiced assiduously and it was the main reference alluded by all Spanish Masters without exception throughout the century.

Key words: Spain; France; Dance; $18^{\text {th }}$ Century; Reception; Court.

\section{INTRODUCCIÓN}

El presente escrito tiene como objeto mostrar el grado de influencia de la danza francesa en la España del siglo XVIII fundamentalmente a través del análisis de los principales tratados de instrucción de este arte conocidos en nuestro país. Dicho estudio es completado con información sobre maestros de danzar reales y algunos documentos referentes a descripciones de fiestas. Esta hegemonía gala se manifiesta también en el resto de naciones europeas aun cuando no reinaran monarcas de origen francés. Mas «lo francés» no se refiere solamente a la práctica musical y coreográfica como tal, sino también al hecho de que estas deben inscribirse igualmente en el marco de una influencia cultural mucho más amplia que abarca la lengua, las artes plásticas, las costumbres y las modas.

Aunque ya durante el siglo XVII se produjeron intercambios en el campo de la danza entre las cortes de Madrid y París, el cambio dinástico de comienzos del siglo XVIII supuso en España un nuevo rumbo para la sociedad. Los sectores más acomodados se esforzaron en ponerse al día imitando las costumbres cortesanas del país vecino y atrajeron hacia el nuestro una pléyade de músicos, cantantes y maestros de danza extranjeros, lo que a su vez motivó fenómenos de reacción evidenciados en diversas manifestaciones de la vida cultural española y que trajeron como resultado una mayor valoración de la danza autóctona, sobre todo en la segunda mitad de siglo.

Hubo incluso un intento por parte de músicos del séquito del Duque d'Anjou (futuro Felipe V) capitaneados por Desmarets ${ }^{1}$, de implantar la música francesa en la corte madrileña. Tal esperanza, sin embargo, fue desvanecida apenas unos meses después de su llegada. Una serie de desencadenantes provocaron tal fracaso: la nación y el estado españoles vivían en conflicto por el advenimiento de un nuevo rey y de una nueva dinastía, la corte se debatía entre las tradiciones hispánicas y las modas francesas, los inevitables malentendidos entre franceses y españoles, la debilidad de Felipe $\mathrm{V}$ y la inconsistencia de sus hábitos de melómano, la hostilidad de la princesa de los Ursinos, las influencias italianas y las dificultades

1. Henry Desmarets (1661-1741). Trabajó al servicio del Rey de España en el periodo comprendido entre 1699-1706. 
LA RECEPCIÓN DEL ESTILO FRANCÉS EN LOS TRATADOS DE DANZA ESPAÑOLES DEL SIGLO XVIII

financieras de la guerra de sucesión española entre otros acontecimientos, provocaron la expulsión de dicho grupo en $1703^{2}$.

Las conexiones artísticas entre España y Francia en esta etapa de nuestra historia han sido objeto de importantes trabajos por parte de estudiosos provenientes de distintas áreas. A Beatriz Martínez del Fresno se debe un estudio sobre los intercambios culturales entre Francia y España a través de la danza, analizando los complejos procesos de identidad, recepción y circulación en los siglos XVIII y $\mathrm{XIX}^{3}$. Jordi Raventós realiza asimismo un análisis de dichos procesos de recepción y transformación de la danza francesa circunscrita a la Barcelona del siglo XVIII haciendo especial hincapié en la capacidad de la danza para articular cierto discurso en relación con el dominio, la disciplina y la presentación del cuerpo.

Por su parte, Guadalupe Mera aporta un resumen interesante del panorama de la danza y el baile en la España ilustrada de Carlos III abordando los géneros de danza cortesana y teatral, la tratadística, las colecciones de música de danza y el baile popular ${ }^{5}$. Además esta investigadora nos habla de las polémicas sobre la construcción de una identidad nacional frente al modelo francés ${ }^{6}$. Clara Rico Osés prefiere hablar de un "cruzamiento de identidades» entre la danza francesa que llega a Madrid a través de la Corte de Felipe V y las danzas populares de carácter español a través del estudio y análisis de fuentes de diversa índole?

2. Consultar el estudio monográfico sobre Desmarets, en concreto el capítulo referente a su estancia en España, a cargo de M. AnToINe, Henry Desmarets (1661-1741). Biographie critique. A la cour d'Espagne et de Lorraine. Paris: La vie musicale en France sous les rois Bourbons. Éditions A. et J. Picard, 1965, pp. 83-118. También Jean Duron e Yves Ferraton, Henry Desmarest (1661-1741): Exils d'un musician dans l'Europe du grand siècle. Editions Mardaga, 2005.

3. MARTínez del FRESNO, B. "Intercambios culturales entre Francia y España a través de la danza: identidad, recepción y circulación en los siglos XVIII y XIX». En MARTínEZ DEL FresnO, Beatriz (ed.). Coreografiar la historia europea: cuerpo, política, identidad y género en la danza. Oviedo: Universidad de Oviedo, 2011.

4. RAVENTÓs I FREIXA, J. "La danza francesa en Barcelona durante el siglo XVIII: recepción y transformación". TRANS 2 (1996). Identidad étnica en el contexto de la globalización y la diversificación de prácticas musicales en países iberoamericanos. II Encuentro Iberoamericano de etnomusicología, Barcelona. Del 30 de junio al 2 de julio de 1995.

5. MERA, G. «La danza, el baile, los saraos, la danza escénica y los bailes populares. Notas y precisiones sobre su estado en la España ilustrada”. En Lolo, Begoña (coord.). Teatro y música en España: los géneros breves en la segunda mitad del siglo XVIII. CSIC y Universidad Autónoma de Madrid, 2008.

6. Mera, G. "Los ilustrados y la danza a principios del siglo XIX: polémicas sobre la construcción de una identidad nacional frente al modelo francés. En MARTínEZ del FrESNO, Beatriz (ed.). Coreografiar Europa, Cuerpo, Política, Identidad y Género en la danza. Ediciones de la Universidad de Oviedo, 2013, pp. 173-199.

7. Rico Osés, C. "De las ceremonias de los bailes». Bulletin bispanique, 114-2, 2012, pp. 645-669. 
Dos documentos manuscritos, ubicados en el País Vasco y Madrid respectivamente, sirven de base a los artículos de Bagües ${ }^{8}$ y Campóo ${ }^{9}$ en los que se demuestra la importante presencia de la danza en la educación de los jóvenes pertenecientes a las clases acomodadas, instrucción llevada a cabo por maestros franceses o formados en el estilo francés, provenientes con frecuencia del área mediterránea. Aunque ambas escuelas - la francesa y la española- convivían en el programa de enseñanza, en 1770 se produjo la supresión de esta última en el Real Seminario de Nobles de Madrid, poniendo fin a una práctica tradicionalmente asentada.

Uno de los principales obstáculos a los que se enfrenta la investigación en danza histórica radica en la inasibilidad del movimiento y su dificultad a la hora de transcribirlo en un papel. Dicho problema que comparte también con la música -aunque esta última en bastante menor grado- quedó algo subsanado con la invención de sistemas de notación ${ }^{10}$ que maestros de danza y coreógrafos explicaban con detalle en sus libros ${ }^{11}$. Dichas fuentes, tanto impresas como manuscritas, proliferaron en la España del siglo XVIII y gozaron de amplia divulgación, siendo la imprenta un medio eficacísimo para la difusión de estos repertorios ${ }^{12}$. Los impresos españoles de danza evidencian en esta época las dos posturas descritas: los hay que siguen fielmente los dictados de la moda francesa aportándonos descripciones de las danzas más emblemáticas como el Minué, Passapié, Amable o Contradanza y también los que pretenden la recuperación de lo «español», que tiene su reflejo en la moda del "majismo» y en el arraigo de formas de danza de extracción popular, como el Fandango, la Seguidilla o el Bolero.

Debido a la complejidad y amplitud del objeto a investigar, este trabajo se ha ceñido al estudio del repertorio coreográfico para ser danzado en el ámbito cortesano, quedando pendiente temas tan trascendentes para entender y completar este fenómeno cultural en nuestro país como la danza en el teatro o en la iglesia, aspectos por desarrollar en futuras investigaciones.

8. BAGÜES, J. «La música y la danza en los proyectos pedagógicos de la Real Sociedad Bascongada de los Amigos del País». Recerca Musicológica, 1988, VIII, pp. 177-131.

9. CAMPóo SchelotTO, D. "Danza y Educación nobiliaria en el siglo XVIII: El método de la Escuela de Baile en el Real Seminario de Nobles de Madrid". Revista del Departamento de Historia del Arte y Música de la Universidad del País Vasco, 2015, n. ${ }^{\circ}$ 5, pp. 157-173.

10. El sistema de notación de mayor calado en el siglo XVIII conocido como chorégraphie, aporta la novedad de emplear signos para describir el movimiento y no descripciones verbales.

11. La primera publicación conocida se debe a R. A. FEullLET. Chorégraphie ou l'art décrire la dance, par caractères, figures et signes démonstratifs, avec lequels on apprend facilement de soy-mêmes toutes sortes de dances. Paris, chez Michel Brunet, 1700. Ed. Facsímil New York, 1968. Posteriormente abundan las traducciones literales o ligeramente ampliadas de esta obra en toda Europa.

12. Consultar Ruíz MaYordomo, M. J. "Danza impresa durante el siglo XVIII en España: ¿inversión o consumo? En Lolo, Begoña y Gosálvez, José Carlos (eds.). Imprenta y edición musical en España (ss. XVIII-XX). Madrid: Universidad Autónoma de Madrid: 2012, pp. 131-144. 


\section{MAestros DE DANZA REALES}

Los más prestigiosos puestos de danza en España estaban en el palacio al servicio de la familia real. Significativa información sobre los maestros de danza reales se conserva en dos fuentes principalmente. La primera está en el Archivo del Palacio Real de Madrid (AGP) en la sección Administrativa, Expedientes Personales $^{13}$. La segunda se encuentra contenida en la Biblioteca Nacional (E-Mn) ${ }^{14}$.

Los documentos originales de ambas fuentes conciernen a nombramientos, pagos de la media anata ${ }^{15}$, peticiones por salarios atrasados, y otras reivindicaciones.

En la casa real había dos puestos de danza principales: uno para los pajes del rey (maestro de dançar de los paxes del rey) y el otro para la reina y sus damas (maestro de dançar de la reyna y sus damas). El servicio en la corte estaba organizado de tal manera que los pajes y sus maestros de danza pertenecían a las reales caballerizas. Esta sección era encabezada por el caballerizo mayor ${ }^{16}$. Un maestro de danza representaba solamente uno de los varios instructores que entrenaban a los pajes del rey. Otras disciplinas usuales en la formación de estos jóvenes eran la música, la esgrima, la equitación y el manejo de las armas.

El maestro de danza de la reina pertenecía a la casa de la reina. Esta sección del palacio era administrada por el mayordomo mayor de la reina ${ }^{17}$. Cuando no había reina regente, este puesto era aparentemente reemplazado por el de maestro de danza de sus altezas.

Los contratos de maestros de danza de los pajes de rey y de la reina eran normalmente de por vida. A veces el mismo maestro mantenía ambos cargos. En otras ocasiones había un maestro diferente para cada puesto. Existía también la figura de instructor asistente de algunos maestros reales. (Ayuda de maestro de su magestad $)^{18}$.

El maestro real recibía por su servicio un salario anual (gajes), así como otras pagas en efectivo y en bienes materiales (ayuda de costa y demás emolumentos). Otros beneficios adicionales podían asumir diferentes formas. Por ejemplo, la casa

13. EsSES, M. «New Information Concerning some Music Research Libraries in Spain». En Fontes artis musicae, 1979, 26, p. 190.

14. Con las signaturas Mss 14020 al 14047.

15. La media anata era una tasa real, igual en valor a la mitad de los ingresos del primer año, que cada empleado debía pagar antes de tomar posesión de un nuevo puesto. "ANNATA" en: Diccionario de la lengua castellana,... Compuesto por la Real Academia Española. Madrid, 1726. Ed. facsímil Madrid, 1964, vol.1, p. 300.

16. La organización del servicio en la corte es discutida brevemente por Ch. E. KANY. Life and Manners in Madrid 1750-1800, Berkeley, 1932, pp. 139-42. En el siglo XVIII los deberes del caballerizo mayor están resumidos en Diccionario de la lengua castellana... Op. cit., vol. 2, 1729, p. 6.

17. Diccionario de la lengua castellana... Op. cit., 1734, vol. 4, pp. 519-20.

18. Esquivel Navarro, J. de: Discursos sobre el arte del dançado, y sus excelencias y primer origen, reprobando las acciones deshonestas. Sevilla, 1642. Ed. facsímil Valencia, Librerías "París-Valencia", 1992. "Mas maestros de Madrid», f. 47r. 
de aposento. Por otra parte, la reina o la princesa a menudo estaban de acuerdo en dar a sus maestros de danza abundante ropa nueva cada año.

A pesar de todos estos beneficios, los maestros de danza reales no siempre estaban seguros financieramente. Las promesas eran una cosa y los pagos, otra. Además, como se ha explicado anteriormente, los maestros de danza tenían que pagar una suma considerable en forma de media anata antes de asumir el puesto. La inflación también causaba serios problemas. Aunque el valor de la moneda española fluctuaba violentamente, el salario de los maestros de danza reales permanecía fijo.

Ya durante la primera mitad del siglo XVII conexiones directas en el campo de la danza habían existido entre las cortes reales de Madrid y París. Quizás uno o más maestros de danza españoles fueron a París a servir a la reina Ana Mauricia, hermana de Felipe IV y esposa de Luis XIII. Es conocido que al menos el español "Jean» López de Gargas sirvió como su musicien entre 1634 y $1640^{19}$.

En la segunda mitad del siglo XVII algunos maestros franceses de danza vinieron a España para trabajar en la corte real ${ }^{20}$. Cuando Marie-Louise d'Orléans (la primera esposa de Carlos II) llegó a Madrid en 1679, su séquito incluía a Charles Charpentier, maître à dancer, y a Claude Mergey cuyo padre (Nicolas Mergey) fue maître à dancer à Paris. El violinista Michel Farinel había sido contratado como responsable principal en la obligación de componer "toute la musique, sinfonie et dances qui seront ordonnez pour le divertissement de leur-dites Majestez Catoliques". El grupo de artistas estaba compuesto de trece cantantes, un clavecinista, una cantante solista, doce sinfonistas-maestros de danza, cuatro oboístas, un ingeniero maquinista y un maquinista adjunto ${ }^{21}$.

Instalada en Madrid, Marie-Louise había hecho venir de Roma al maestro de danza Nicolas Fonton que, en agosto de 1702, alegó "que había estado en París por orden de la reina para recopilar las nuevas danzas» ${ }^{22}$. El Rey fija sus gages en Barcelona en 200 pistoles por año.

19. Esses, M. Dance and Instrumental 'Diferencias' in Spain during the 17 th and early $18^{\text {th }}$ Centuries. New York: Pendragon Press Stuyvesant, 1992. vol. 1, p. 500.

20. Sobre este interesante momento cultural en la corte española consultar CARRERAS, J. J. "L'Espagne et les influences européennes: la musique française à la cour d'Espagne (1679-1714)». Échanges Musicaux franco-espagnols XVIIe-XVIIIe siècles. Actes des Rencontres de Villecroze, réunis par François Lesure, Académie Musicale de Villecroze, 15 au 17 octobre 2000, pp. 61-82.

21. El principal estudio documental de este grupo de músicos franceses en España ha sido realizado por M. BENOIT en su artículo «Les musiciens français de Marie-Louise d'Orléans, Reine d'Espagne». Revue Musicale, 1953-1954, 226, pp. 48-60. Basado en un documento original en París, Archives Nacionales, Minutier Central CV 887. Trabajo completado por STEIN, L. K. Songs of Mortals, Dialogues of the Gods. Music and Theatre in Seventeenth-Century Spain. Oxford: Clarendon Press, 1993, pp. 328 y ss.

22. Cf. carta de la princesa de los Ursinos al marqués de Torcy, fechada en Madrid el 19 de agosto de 1702, publicada por el duque de la Tremoille, Madame des Ursins et la succession d'Espagne. Nantes, 1903, vol. 1, pp. 79-89, cit. por AnToIne, M. Henry Desmaret (1661-1741). Biographie critique. Paris: Éditions A. et J. Picard, 1965, p. 106. Nicolas Fonton, de origen romano, fue maestro de danza 
No hay documentación de los músicos franceses en el Archivo del Palacio Real, por haber regresado a Francia sin ser considerados integrantes de la casa de la reina, a la que se quiso aislar de su trato, rodeándola de un personal de servicio español ${ }^{23}$. Para Stein los músicos franceses de Marie Louise no tuvieron oportunidades en España y fueron sistemáticamente ignorados por la corte ${ }^{24}$, lo que explica la laguna en los expedientes personales del Archivo de Palacio. Benoit halló en Francia toda la documentación relativa a estos músicos, presencia musical que se reforzará en la década de 1690, con Mariana de Neoburgo.

Otros maestros de danzar que contribuyeron al desarrollo de este arte en España durante el siglo XVIII fueron los Christiani de $\mathrm{Scí}^{25}$, presumiblemente oriundos de Italia, al menos por vía paterna, pero nacidos y formados en el área cultural de Dinamarca y Suecia. No es descabellado suponer que estos profesionales instruyeran a sus discípulos principalmente en la danza francesa, estilo imperante en las cortes escandinavas.

Por otro lado, solo se ha podido documentar la vinculación directa de Sebastián Christiani de Scío a la Casa Real de Felipe V a partir de 1737, en que siendo allí maestro de danza el francés Miguel Godreau, es favorecido por Real Decreto del 19 de junio con la mitad del sueldo de tal titular para suplir las enfermedades y ausencias de este, y cinco meses después (17 de noviembre) se le añaden, por nuevo Real Decreto, 6 doblones de aumento "por cada una de las Señoras Infantas desde el día que empezó a dar lección a Sus Altezas» ${ }^{26}$.

En España no hay academias reales dedicadas a la danza y la música como ocurriera en Francia. La Académie Royale de Musique había sido fundada en París en 1672. Además en 1713 Luis XIV propuso que fuera ampliada e incluyera escuelas de danza y música. Esta Académie no era un lugar para la reflexión, sino más bien la interpretación e incluía todas las fuerzas necesarias para representar eventos ambiciosos: orquesta, coro, solistas, bailarines profesionales, tramoyistas y decoradores.

Gracias a la documentación conservada, tenemos conocimiento de maestros de danza que ejercieron sus labores en el ámbito cortesano, de sus obligaciones, así como de la situación laboral de los mismos en sus respectivos puestos de trabajo. Debido a la importancia de esta disciplina en la formación de los jóvenes, la

de la Reina después de los infantes de España y murió poco antes de Septiembre de 1715. AGP, Expedientes personales, C. ${ }^{\text {a }} 371$, dossier Fonton, n. ${ }^{\circ} 21$.

23. SAnHuesa Fonseca, M. "Carlos II y las "Dancerías de la Reyna": violones y danza en las postrimerías de la casa de Austria». Revista de Musicología, 1997, XX, 1, p. 267.

24. SteIn, L. K. Songs of Mortals, Dialogues of the Gods... Op cit., pp. 327-328.

25. Siemens Hernandez, L. "Sebastián Christiani de Scío y su familia: contribución a los maestros de danzar en la España del siglo XVIII. Revista de Musicología, 1997, XX, 1, pp. 323-329.

26. AGP. Casa de la Reina. Libro de Registros N. 175 : "Grefier, libro de informes 1718-1739", fol 666v. Vid. También: Felipe V. Casa Real, leg. 292: Relación de los gastos y débitos a los criados y dependientes de la Cámara, Capilla, Casas y Caballerizas reales formadas de orden del Rey. 
figura del maestro de danza real gozaba de alta consideración y representaba el estadio más alto al que podía aspirarse. En la corte española trabajaron profesionales provenientes de Francia, Italia y otros países que se ocuparon de divulgar la danza francesa, estilo internacional predominante que convive con la tradición hispánica. Este hecho debe ser observado como un encuentro cultural descartando la visión forzada de estilos nacionales enfrentados.

\section{El ESTILO FRANCÉS EN LAS FUENTES COREOGRÁFICAS ESPAÑOLAS}

Una de las principales dificultades a la hora de reconstruir una danza es determinar la relación precisa entre los movimientos y el acompañamiento musical puesto que una sucesión de pasos no es suficiente para fijar la organización temporal de la música ${ }^{27}$. En España las fuentes coreográficas desde finales del siglo XVI y durante todo el XVII consisten en descripciones de pasos y otros aspectos relativos a la danza pero carecen de material musical.

Con respecto al siglo XVIII, la reconstrucción de algunas de las danzas sería menos problemática debido al hecho de que los manuales españoles adoptan el sistema francés de notación coreográfica presentado en los tratados de R. A. Feuillet $(1700)^{28}$ y P. Rameau $(c a .1725)^{29}$. En este sistema los símbolos para los pasos de la danza son colocados en una línea que representa la trayectoria del bailarín en el suelo. Esta línea está dividida por pequeñas rayas transversales que corresponden a los compases de la música, cuya melodía aparece escrita en pentagrama en la parte superior de la página.

Las fuentes coreográficas españolas pueden dividirse en dos grupos:

- Aquellas que datan de finales del siglo XVI y todo el XVII.

- Aquellas que datan del siglo XVIII.

Los dos grupos son bastante distintos en el repertorio, método de presentación, y tipo de lector al que van dirigidas. Además esta división refleja el gran cambio en el estilo en la danza y en el repertorio entre la aristocracia española alrededor de 1700 por influencia francesa.

La expansión de la danza francesa fue facilitada gracias al uso del sistema de notación conocido como chorégraphie. El sistema de chorégraphie fue primeramente publicado en 1700 por Raoul Auger Feuillet, quien decía ser su inventor.

27. Ellis Little, M. "The Contribution of Dance Steps to Musical Analysis and Performance: 'La Bourgogne'». Journal of the American Musicological Society, 1975, 28, pp. 112-30.

28. Feuillet, R. A. Chorégraphie ou l'art décrire la dance, par caractères, figures et signes démonstratifs, op. cit.

29. RAmEau, P. Abbrégé de la nouvelle méthode dans l'art de écrire ou de tracer toutes sortes de danses de ville. Paris, ca. 1725. Ed. facsímil Westmead, 1972. 
LA RECEPCIÓN DEL ESTILO FRANCÉS EN LOS TRATADOS DE DANZA ESPAÑOLES DEL SIGLO XVIII

Además, el 25 de agosto de 1699, Feuillet obtuvo del rey los derechos exclusivos para publicar todos los libros de danza en Francia por un periodo de seis años.

El otro maestro de danza que se disputa la invención de un sistema de notación fue Pierre Beauchamp. Durante aproximadamente 22 años sirvió como maître à danser de Luis XIV. A lo largo de su carrera también ocupó el cargo de directeur de l'Accadémie de Danse y compositeur des ballets du roy. Beauchamp asegura que había inventado la chorégraphie un poco antes de 1680, sin embargo falló al establecer los derechos legales en la materia. La única fuente de su obra, según Derra de Moronda, es un manuscrito sin fecha en el que aparecen los movimientos de una Sarabande usando la chorégraphie $e^{30}$.

La influencia de la danza francesa entre la nobleza es demostrada por tratados coreográficos escritos en español y publicados durante los primeros dos tercios del siglo XVIII. El primer tratado, de B. Ferriol y Boxeaus, fue de hecho publicado en el reino de Nápoles en 1745, aunque existe una edición resumida impresa en Málaga el mismo año. Otro ejemplar se editó en Capua, en 1745, conservado en la Biblioteca Nacional de Madrid con la signatura M. $860^{31}$.

El tratado está basado en varias publicaciones anteriores y manuscritos escritos por Ferriol que fueron reunidos y editados por Joseph Testore. Consiste en 14 páginas introductorias, seguidas de 302 páginas que son divididas en tres grandes secciones $^{32}$. La notación coreográfica francesa es usada solo en los dos capítulos finales de la tercera sección ${ }^{33}$.

Ferriol afirma que estudió con cuatro maestros diferentes durante el período de siete años, pero no da sus nombres. Además añade que estuvo en contacto con los más instruidos bailarines de varios países. Más tarde menciona a seis relevantes coreógrafos franceses: Beauchamp, Feuillet, Balon, Pecour, Desais (Dezais), y Rameau. Declara que su obra es la primera explicación comprensible de la danza

30. Derra de Moroda Dance Archives, Mss DdM 797, Sarabande de M\{onsieu\}r de Beauchamp. Salzburg, Universität Salzburg, Institüt für Musikwissenschaft. Facsímil de una página en DERRA DE Moroda, F. "Chorégraphie, the Dance Notation of the Eighteen century; Beauchamp or Feuillet?». The Book Collector, 1967, 16, pl. 1, p. 464.

31. Ferriol y BoXeraus, B. Reglas útiles para los aficionados a danzar. Provechoso divertimiento de los que gustan tocar instrumentos. Y polýticas advertencias a todo género de personas. Adornado con varias láminas. Dedicado a la s\{acra\} m\{agestad\} del rey de las dos Sicilias, Ec. Su autor d\{on\} Bartholomé Ferriol y Boxeraus, único author en este idioma de todos los diferentes passos de danza francesa, con su brazeo correspondiente, chorografía, amable, contradanzas, Ec. Capoa: a costa de Joseph Testore, mercader de libros, a la calle Nueva. Año de MDCCXLV. Con licencia de los superiores.

32. Ferriol y Boxeraus, B. Op. cit. Tratado I. "Donde se contienen todos los diferentes passos de la danza francesa» (13 capítulos), pp. 1-130; Tratado II. "Donde se contiene el brazeo correspondiente en cada passo" ( 4 capítulos), pp. 131-178; y Tratado III. "Que contiene la demonstración y declaración de algunas danzas de corte, corographía, y distinctas contradanzas" (4 capítulos), pp. 179-298.

33. Ferriol y Boxeraus, B. Op. cit. Tratado III, cap. 3 «De la explicación de la chorografía, por la qual se enseña el modo de escribir todos los passos, posiciones, y todo género de danzas", pp. 212242 (34) y cap. 4 "De las etiquetas y explicación de las contradanzas", pp. 242 (34)-298. Los números de página entre paréntesis son los erróneos dados en el original. 


\section{E X P L I C A C I O N}

\section{DEL DANZAR A LA FRANCESA.}

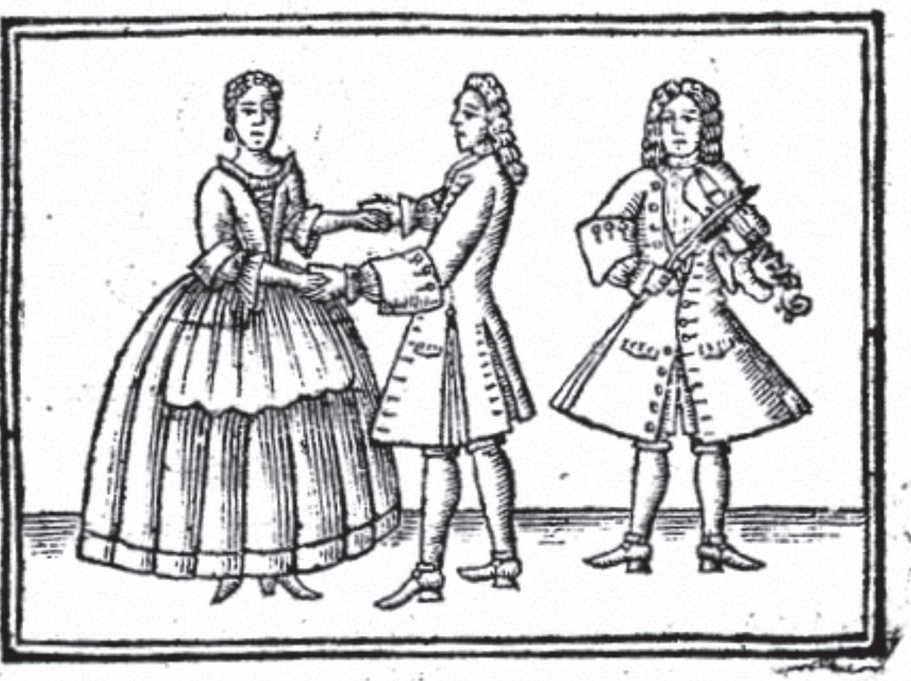

$$
\text { OPOSICION, QUE COSAES }
$$

T A Opoficion no es mas, que una jufta propo: 1 ficion de apartar, ò arrimar los pies coa una diftancia moderada, donde el cuerpo eftc en fu equilibrio, fea para andar, ò fea para baylar.

Notefe, que es menefter faber bien las cino Opoficiones que fe figuen, para bacer bien los pafjoi con per. feccion, afsi para andar por la calle, como para danzar.

\section{A $\varepsilon$} FL

Ferriol y BoXeraus, B. Reglas útiles para los aficionados a danzar. Provechoso divertimiento de los que gustan tocar instrumentos. Y polýticas advertencias a todo género de personas. Capoa: a costa de Joseph Testore, mercader de libros, a la calle Nueva. Año de MDCCXLV. Con licencia de los superiores. E-Mn M 860. 
LA RECEPCIÓN DEL ESTILO FRANCÉS EN LOS TRATADOS DE DANZA ESPAÑOLES DEL SIGLO XVIII

francesa en español. Su tratamiento del tema es muy extenso e incluso incluye una descripción de las convenciones de etiqueta que deben seguirse cuando alguien te invita a bailar durante un sarao o máscara ${ }^{34}$.

Ferriol emplea el sistema de notación francés en su tratado y lo alaba como sigue:

El mejor y más fácil esquema que ha sido inventado en esta disciplina es la chorografía. Gracias a su uso, no solo uno puede repasar las danzas que ha aprendido, sino también puede interpretar nuevas danzas, incluso aquellas que nunca ha visto, sin un maestro. Esto se hace con la misma facilidad con la cual uno canta o toca música, incluso nuevas piezas. Hay dos tipos de chorografía, la vieja y la nueva. El tipo antiguo fue inventado por el señor Feuillet, y el nuevo por el señor Rameau. Debido a que el último sistema es más fácil y claro, es el que explicaré para evitar confusión al que empieza ${ }^{35}$.

Aunque Ferriol frecuentemente intercala sus propios comentarios, gran parte de su tratado consiste en traducciones literales de las definiciones y explicaciones de Rameau. La única sección en la que Ferriol no sigue los escritos de Rameau es el capítulo final de su tratado donde trata de las contradanzas. Ferriol casi con toda certeza las recopila de otras fuentes francesas, pero estas permanecen sin ser identificadas.

Prosigue Ferriol diciendo:

[...] Si alguno quisiere saber los Passos, que contiene la Danza Española (la que no explico por no estar en moda en funciones serias) como assimismo otras curiosidades de ellas, lea el Libro que sobre este assumpto escribiô el Sevillano Esquibel, en el qual al Capitulo III. folio 25. expressa con evidentes razones, que el Discipulo debe pagar al Maestro el mes adelantado, y ser por muchos motivos provechoso à los que aprenden este Arte.

Supuesto que està mui en moda el Bracear con los Passos, voy à dàr sus Reglas, y los medios mas faciles, para executar con la debida perfeccion el Braceo, que corresponde à cada distinto Passo; pues le presta la delicadeza que requiere esta Danza. Por cuya razon no pretendo dilatarme mas en este assumpto, à causa de que el Libro quede en tamaño proporcionado, y haya lugar para poner la Musica, y explicacion de las Contradanzas, y demàs Bailes que estan en moda, y que se queda llevar en la faltriquera, que sucede mui de ordinario que los Aficionados quieren danzar los Bailes de su gusto, y no encontrarse quien los sepa tocar, sin tener la Musica presente: y tambien, porque facilmente se olvidan los Bailes, y teniendo este Librito con solo el divertido repasso, los podràn executar con destreza, avisando que en otro

34. Ibid., tratado I, cap. 9, pp. 57-64 "De las ceremonias de los bailes", que concluye con una descripción de las formalidades observadas en la corte francesa. Esto probablemente está extraído de la obra de Rameau, P. Le maître à danser. Paris, 1725, pt. I, cap. 16 «Du cérémonial que l'on observe au grand bal du roy", pp. 49-54.

35. Ibid., tratado III, cap. 3, pp. 212-213. 
Tomo que tengo intencion de dàr à luz mui presto, havrà lo restante de este Arte, para mayor adelantamiento de la juventud.

El Tratado III contiene la demostración de algunas danzas de corte, su coreografía y distintas contradanzas. Comienza sobre el modo de danzar el Minuete y el Passapie con todas sus figuras. Prosigue con el Amable. Se llama esta danza en francés Aimable Vainqueur, que quiere decir "Amable Vencedor" y para Ferriol es el más importante de los Bayles Serios. Con respecto a la música que acompaña esta danza el autor añade dos versiones, una sencilla y la otra con complicados ornamentos consistentes en grandes formulas melódicas muy virtuosísticas así como dobles cuerdas y arpegiados, escritura que recuerda a Corelli y que demuestra la influencia de dicho autor en España ${ }^{36}$.

Además del Minuete, las danzas de más diversión, y más apreciables en el gusto de la juventud, son las Contradanzas, pues la mayor parte de las funciones se reducen a piezas de este tipo; atendiendo a esta circunstancia, el estar muy de moda y que fácilmente se olvidan debido a la diversidad que hay en estas y sus figuras, Ferriol añade en su Libro la explicación de algunas de ellas y los distintos estilos en danzarlas ${ }^{37}$.

Enumera seguidamente nombres de Contradanzas de distintas características y según sus propias palabras para todas las épocas del año: las de verano son las de compás de Minuete, las de primavera las que tienen de Alegro y Minuete y las de invierno son las violentas. (¡Se supone que para entrar en calor!) ${ }^{38}$. Y finaliza prometiendo muchas Contradanzas nuevas, y otros Bayles de moda en un segundo tomo que por desgracia no se conserva ${ }^{39}$.

El segundo tratado coreográfico español de este periodo fue escrito, grabado e impreso por P. Minguet y Yrol en Madrid. Hay cinco copias diferentes de este libro de danza las cuales se conservan en la Biblioteca Nacional de Madrid con la signatura R. 14649. Se trata de una obra en cuatro partes, cada una de las cuales fue aparentemente impresa en distintas fechas.

La Parte I se conserva en su tercera edición y fue publicada en 1758. Consiste en 6 páginas de prefacio, seguidas de 40 páginas numeradas. Incorpora 25 dibujos y diagramas, pero no hace uso del sistema coreográfico de notación ${ }^{40}$. La

36. Ibid., tratado III, cap. 3, pp. 232-241.

37. Ibid., tratado III, cap. 4, pp. 250-264.

38. Ibid., tratado III, cap. 4, pp. 264-297.

39. Ibid., tratado III, cap. 4, p. 298.

40. Minguet y YRol, P. \{Parte I\} Arte de danzar a la francesa, adornado con cuarenta y tantas láminas, que enseñan el modo de hacer todos los passos de las danzas de corte, con todas sus reglas, y de conducir los brazos en cada passo; y por chorographía demuestran cómo se deben escribir, y delinear otras: obra muy conveniente no solamente a la juventud, que quieren aprender el bien danzar, sino aun a las personas civiles, y honestas, a quien les enseña las reglas para bien andar, saludar, y hacer las cortesías, que convienen en qualquier suerte de personas. Corregido en esta tercera impressión por su autor Pablo Minguet e Yrol. Madrid, 1758. 
LA RECEPCIÓN DEL ESTILO FRANCÉS EN LOS TRATADOS DE DANZA ESPAÑOLES DEL SIGLO XVIII

Parte II con la signatura R.14649 consiste en 56 hojas sin numerar sin portada. Esta copia podría estar incompleta por faltar las dos primeras y las dos últimas hojas encontradas en el ejemplar con la signatura R.14607. Por desgracia no hay fecha de publicación ${ }^{41}$. En esta parte Minguet da la música y explicaciones coreográficas para varias danzas, usando para la mayor parte el sistema de notación Feuillet. La Parte III consiste en 20 páginas numeradas sin ninguna notación coreográfica, seguidas de una página desplegable de música que da la melodía y bajo en pentagrama para cinco contradanzas. Tampoco hay fecha de publicación ${ }^{42}$. La Parte IV conservada en su segunda edición, fue publicada en 1764. Consiste en 14 páginas numeradas sin notación coreográfica ${ }^{43}$.

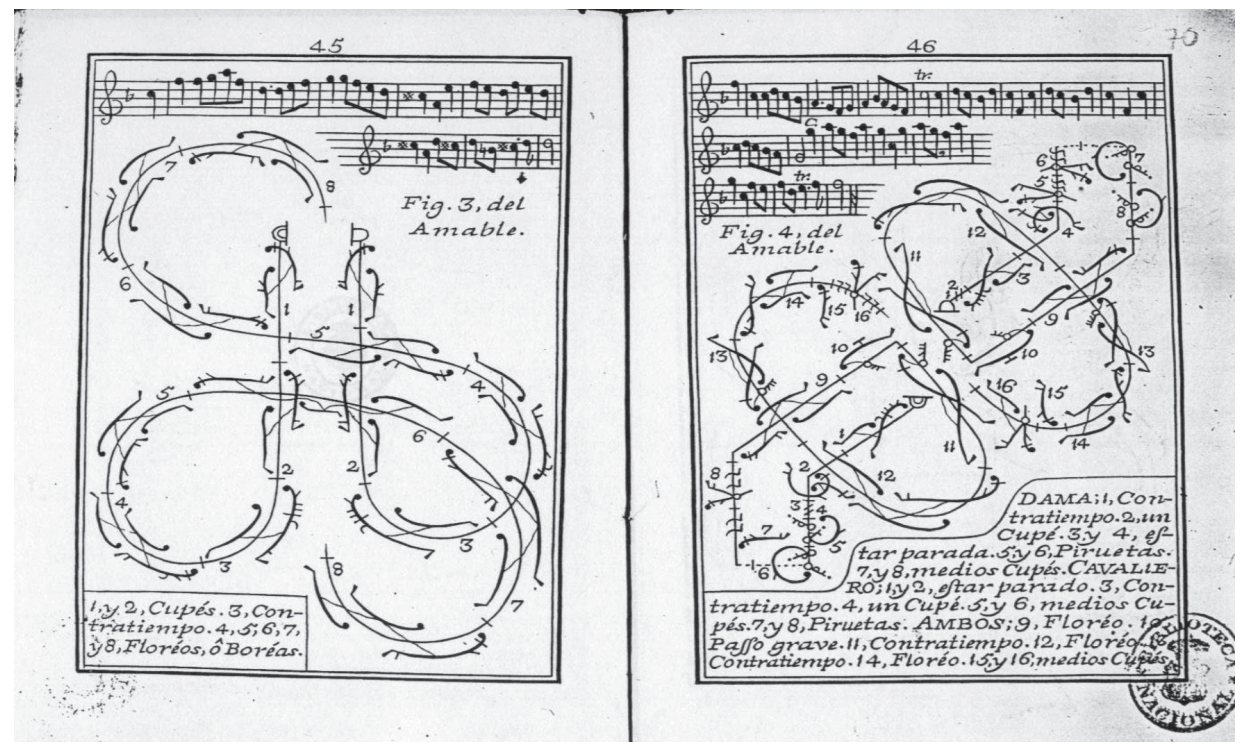

Minguet Y YROL, P. \{Parte II El noble arte de danzar a la francesa, y española. Madrid, sin fecha. E-Mn R. 14607.

41. Minguet y Yrol, P. \{Parte II El noble arte de danzar a la francesa, y española; adornado con LX láminas finas, que enseñan el modo de hacer todos los passos de las danzas de corte, con sus reglas, y de conducir los brazos, en cada passo; y por chorographía demuestran cómo se deben escribir otras. Madrid, sin fecha.

42. Minguet y Yrol, P. \{Parte III\} Quadernillo curioso, de veinte contradanzas nuevas, escritas de todas quantas maneras se han inventado hasta aora; tienen la música muy alegre, y con su baxo: compuestas por Pablo Minguet. Madrid, sin fecha.

43. Minguet y Yrol, P. \{Parte IV\} Breve tratado de los passos del danzar a la española, que oy se estilan en las seguidillas, fandango, y otros tañidos. También sirven en las danzas italianas, francesas, e inglesas, siguiendo el compás de la música, y las figuras de sus bayles. Corregido en esta segunda impressión por su autor Pablo Minguet. Madrid, 1764. 
En la Parte II, al final de una lámina en la que muestra los movimientos de danza para "La idea buena, contradanza buena" (¿nueva?) usando otros signos diferentes de los franceses para representar a los bailarines, Minguet declara:

Lector, esta es la forma perfecta para anotar bailes; y no las maneras que he visto que no pueden entenderse si no hay alguien que te las explique. En esta disciplina, donde la explicación no tiene valor sin la ilustración, he sido el único en España desde el año 1733 en usar la susodicha notación coreográfica para las danzas. Vendo estas danzas en grupos o separadamente ${ }^{44}$.

Sin embargo, lo que publicó en 1733 no se conoce. Probablemente se trate del mismo cuaderno que de acuerdo con Saldoni fue anunciado en la Gaceta Oficial de Madrid el 24 de diciembre de $1764^{45}$.

En la Parte III, p. 20 (16) Minguet añade:

En el año 1733 publiqué la primera edición, después de haber impreso diferentes tipos de obras, y cada vez he añadido algunas finas danzas y contradanzas. (Fui el primer autor en España en este tema). Se que algunos entusiastas han hecho buenos progresos sin profesor. Imprimiré el charamán, la alemanda, y otras danzas que están de moda en las cortes europeas; poseo los libros de los mejores autores que han escrito sobre esta disciplina ${ }^{46}$.

En las Partes I a III de su tratado Minguet trata exclusivamente de danzas francesas. Casi enteramente toma material de tratados de otros autores, pero no menciona sus fuentes. Solo en un punto, después de la explicación de un Passapié, hace referencia a otros teóricos como Feuillet, Pécour, Dezais, Ricart y Balo (es decir, Balon). La identidad de Ricart no está clara. Quizás se trate de Antoine Germain Richard, quien fue miembro de la Académie Royal de Danse en París a finales del siglo XVII.

En la Parte II de su tratado Minguet emplea el sistema antiguo de notación coreográfica publicado por Feuillet. Su presentación de la notación de castañuelas y el tratamiento coreográfico de las Folías corresponden exactamente a las explicaciones dadas por Feuillet en su tratado de $1700^{47}$.

44. Minguet y Yrol, P. Op. cit., pt. II, lámina 5.

45. Saldoni y Remendo, B. Diccionario biográfico-bibliográfico de efemérides de músicos españoles. Madrid: Imprenta de Antonio Pérez Dubrull, 1880. Ed. facsímil por Jacinto Torres. Madrid, INAEM, Centro de Documentación Musical, vol. 4, 1986, p. 208. La obra en cuestión se titula: Quadernillo nuevo que explica los passos de danzar a la española, saber tañer la guitarra, y el tiple y otras curiosidades. No se conserva ninguna copia.

46. El título charamán es probablemente una corrupción de la palabra francesa charmant.

47. Minguet y Yrol, P. Op. cit., pt. II «Figuras para saber tañer las castañuelas con la música en las danzas italianas, y españolas», lámina 34, es equivalente a Feuillet, R. A. Chorégraphie... Paris, 1700, parte I "De la batterie des castagnettes», pp. 100-101. Similarmente tanto la música como la notación en Minguet, pt. II "Folías primera diferencia», lámina 42, se encuentran en Feuillet, parte I "Couplet de folie d'Espagne avec les bras et la batterie des castagnettes", p. 102. 
En esta Parte II Minguet también se basa en otras fuentes francesas que usan el antiguo sistema de chorégraphie como se demuestra en su explicación de tres danzas de Pécour ${ }^{48}$.

Solo en la Parte IV de su tratado Minguet discute la danza española. Aunque no describe en detalle la interpretación de ningún tipo particular de danza, da breves explicaciones verbales de 45 pasos, 36 de los cuales son nombres similares de aquellos usados mucho antes en Esquivel Navarro ${ }^{49}$ y Jaque ${ }^{50}$.

Mientras que el tratado de Ferriol muestra que muchas de las danzas típicas españolas cayeron en desuso entre la aristocracia, las observaciones de Minguet indican que otras fueron muy transformadas debido a la influencia de las prácticas francesas. Por ejemplo, Minguet dice que los principios básicos de la coreografía francesa también son aplicables a las danzas españolas. Además, puntualiza que los pasos españoles pueden usarse en danzas extranjeras, y pasos extranjeros en danzas españolas como las Seguidillas.

Otra fuente coreográfica escrita en español en esta época se debe a Joseph Ratier. Una aprobación de este, impresa en Sevilla, se conserva en la Biblioteca Nacional $^{51}$. Existe una copia manuscrita de Barbieri con las aprobaciones ${ }^{52}$. De acuerdo con la portada el original fue publicado en Madrid. No hay una fecha, pero probablemente se publicara en 1759 o un poco antes, porque todas las aprobaciones datan de 1758 o 1759.

Presumiblemente Ratier había nacido en Francia. En la fecha de la publicación era miembro de la Academia Real de Música de París y estaba activo como maestro de danza en Cádiz ${ }^{53}$. Según sus propias palabras, había empezado a trabajar en este tratado 20 años antes, y originariamente lo escribió en francés antes de haberlo traducido al español. La naturaleza totalmente francesa de sus ideas coreográficas está reflejada por el hecho de que fue capaz de obtener grandiosas aprobaciones de Francia para su libro. Hay incluso una aprobación, fechada en París, el 25 de agosto de 1758 firmada por todos los maestros de danza pertenecientes a la Real Academia de Música. El primer firmante fue Laval, maestro de

48. Ibid., pt. II "Demonstración del minué de Alcides", láminas 29-30; "Demonstración de la Bretagne», láminas 35-41; y «El amable, con otra chorographía», láminas 43-48. La mismas danzas aparecen en el segundo tratado de Rameau donde la atribución a Pécour es explícita: Rameau, P. Abbrégé de la nouvelle méthode... Paris, ca. 1725, pt. II "Menuet d'Alcide», pp. 45-50; "La Bretagne», pp. 65-71; $\mathrm{y}$ "Aimable vainqueur", pp. 39-44.

49. Esquivel Navarro, J. de. Discursos sobre el arte del dançado, y sus excelencias, Op. cit.

50. JaQue, J. A. Libro de danzar. E-Mn Mss 18580/5 y E-Mn Barbieri Mss 14059/15.

51. RATIER, J. Aprobación de los más famosos maestros prácticos y teóricos de la Europa, sobre las Observaciones, principios y reglas del arte de la danza. Sevilla, sin fecha. E-Mn M. 1258.

52. RATIER, J. Observación I sobre el arte de la danza, de las muchas compuestas por don Joseph Ratier, antiguo académico en danza de las Academias Reales de Música de Francia, y maestro de ella en Cádiz, aprobadas por los más famosos maestros prácticos, y teóricos de la Europa, como se verá al fin de este discurso. Madrid, sin fecha. E-Mn Barbieri Mss 14059/16.

53. De acuerdo con lo que dice la portada. 
danza de la familia real de Francia, y compositor de los bayles para el Rey. Este era probablemente el mismo Laval ${ }^{54}$ que había alcanzado renombre en la corte francesa en 1731, siendo llamado a suceder a su tío, el afamado bailarín, coreógrafo y pedagogo Mr. de Ballon ${ }^{55}$ como maître à danser des Enfants de France.

Uno de los propósitos de Ratier al escribir el libro es dar instrucción a los maestros con pocos conocimientos. El está muy en contra de los tratados del periodo que aseguran poder enseñar al lector sin ayuda de un profesor (tales como las publicaciones de Minguet y Yrol). Según Ratier, los servicios de un maestro son indispensables. No hay duda de que esta actitud fue muy apreciada por sus colegas franceses, que por su parte le brindaron una entusiasta aprobación.

Otras dos obras postreras, los tratados de Roxo de Flores ${ }^{56}$ y Cairón ${ }^{57}$ siguen reflejando la influencia francesa en la danza de nuestro país. El capítulo VII del primer autor comienza con una panorámica de los bayles de España antiguos y modernos hasta llegar al bolero. A esta exposición, le sigue el párrafo titulado «Del Bayle Francés» transcrito a continuación:

La Escuela Francesa entre los Españoles es de ejercicio muy moderno, según la noticia comun de los hombres ancianos: no dudo que con motivo de la proximidad á aquel Reyno, se adelantaria en algunas provincias, como fué en Cataluña, donde es muy freqüente, aun entre los Artesanos, que son muy diestros en practicarla.

Por cosa singular se baylaba, hace poco, en el interior de España el Minuet, limitado á una Música de poco gusto, acompañado á veces de ciertas Letrillas, qual era:

$$
\begin{gathered}
\text { Sujeto á la cadena } \\
\text { Lloro mi triste pena } \\
\text { Lloro, lloro } \\
\text { Lloro mi triste mal \&c. }
\end{gathered}
$$

Por este ó equivalente estilo se hallan otras Canciones con el nombre de Minuet en los villancicos y motetes destinados á elogiar algun Heroe, aludiendo acaso á la gravedad del Bayle, que contempla ser el mas sério Mr. Brossard. A los Franceses se hace Autores de él, cuyo origen fue en Poitou. Sus pasos y movimientos son como escala para los demas Bayles de la Escuela, porque todos admiten alguna cosa del Minuet ó Menuet. Aquella Nacion tomó de los Ingleses, Alemanes, é Italianos, lo que la pareció acomodado para sus representaciones Cómicas, y se perfeccionó en el Bayle reynando Luis XIV, que creó en París el año de 1661 la Academia Real de Danza,

54. Antoine Bandieri de Laval (1688-1767).

55. Claude Ballon (1676 - 1739).

56. ROXO DE FLORES, F. Tratado de recreación instructiva sobre la Danza: su invención y diferencias. Madrid, Imprenta Real, 1793.

57. CAIRón, A. Compendio de las principales reglas del baile traducido del francés por A. Cairón y aumentado de una explicación exacta y método de ejecutar la mayor parte de los bailes conocidos en España, tanto antiguos como modernos. Madrid, Imprenta Repullés, 1820. Existe un ejemplar en E-Mn con la signatura M 868. (En gran parte traducido de Feuillet. La parte relativa a las danzas nacionales, es la única original de la obra). 
LA RECEPCIÓN DEL ESTILO FRANCÉS EN LOS TRATADOS DE DANZA ESPAÑOLES DEL SIGLO XVIII

expidiendo á este fin sus Letras que se comprobáron y cumplimentáron en el Parlamento al siguiente de 1662 con la prerrogativa de que los Académicos de Número, que habian de ser trece, ademas de un Presidente y un Director, tuvieran el privilegio, como tambien sus Hijos, de enseñar el Arte de Danzar: que se juntasen una vez al mes en casa del Director para tratar lo respectivo á su profesion sin perder de vista uno de sus principales objetos, que era instruir á los Discípulos, y habilitarlos para la Opera. Nosotros podemos formar en el dia suficiente idea de estos Bayles reglados, y de la gran variedad de Contradanzas sueltas por la disposición de los Teatros de España, cuyas noticias tienen mucho mérito, comparadas con las generales é indefinidas, que acerca de sus nombres, y execucion se han querido publicar por personas poco exâctas en la curiosa investigación y estudio de la materia.

El lenguaje francés técnico de los pasos y las danzas francesas que nombra en su libro Cairón como El Minué, Contradanza, Gabota o Paspié, aparecen mezcladas con un número considerable de piezas españolas y americanas, a saber: Pavana, Folias, Pasacalle, Zarabanda, Bolero, Fandango, Seguidillas manchegas, Canario, Danza prima, Gira, Gaita gallega, el Bizarro, la Jota, Landún, el Villano, Zarambeque, Mitote, Jorco, Caballero, Paisana, Pela, la Palmadica, la Gallarda o el Cumbé. El material importado convive con la tradición.

La siguiente fuente manuscrita, localizada en la Biblioteca de Oporto está escrita en español con fecha de 1751. Dicho manuscrito contiene diferentes danzas francesas de corte usuales en las reuniones o $\operatorname{saraos}^{58}$ y está dedicado al señor Don Manuel de Figueroa. Fue traducido de su original en francés por Don Felix Kin... (por desgracia ilegible), maestro de danza de la ciudad de Oporto ${ }^{59}$. Todas las danzas están en notación Feuillet y aparecen junto con el nombre de sus autores.

Nicolas Rodrigo Noveli (o Novelli) ${ }^{60}$ es el autor de un documento de reciente hallazgo, fuente que se encuentra ubicada en la Academia de Bellas Artes de San Fernando de Madrid ${ }^{61}$.

La primera parte del manuscrito trata sobre los principales movimientos de la Danzeria, posiciones del cuerpo, pies, brazos y movimientos. Aunque a primera

58. KInSKI, F. Libro de Diferentes Danzas que se estilan Bailar en saraos Politicos y en Palacios de Distintas cortes, para el señor D_n Manuel de Figueroa: Choregraphie o arte para saber danzar todas suertes de danzas por Choregraphie con caracteres, figuras i señales demonstrativas. Traducido de su original por D_n Felix Kin...Maestro de Danza en esta Ciudad de Oportu. Oportu, 20 Henero de 1751. P-Pm Mss sin numerar.

59. Se trata de Felix Kinski según Lancelot, F. La Belle Dance. Catalogue raisonné fait en l'an 1995. París: Van Dieren éditeur, 1996, p. 371.

60. Se desconoce hasta la fecha un estudio biográfico de Noveli sin embargo parece ser que publicó algunas obras entre ellas una CARTILLA en que se proponen las Reglas para torear à caballo y practicar este Valeroso Noble Exercicio con tona destreza (1726) y Crisol especulativo, demostrativo, práctico, Matemático de la destreza (1731). La verdadera destreza es una escuela de esgrima española.

61. Noveli, N. R. Choregraphia figurativa y demostrativa del Arte de Danzar, en la forma española. Compuesto por Don Nicolas Rodrigo Noveli, dedicado al prior del Consulado de S.n Sebastián que fuere electo el año tercero del próximo siglo. En Madrid año de 1708. 
vista parece una traducción del Tratado de Feuillet -seguramente por eso Noveli lo llama Choregraphia - se trata en realidad de una descripción de los principales pasos de la danza española escritos en dicha notación, cuestión trascendental, ya que las fuentes de danza española de los siglos XVII y XVIII utilizan descripciones verbales para los pasos y movimientos, siendo algunas de ellas no del todo claras.

A continuación se expone lo que el autor llama las Líneas de que participa la Danzería, es decir, las evoluciones en el espacio del repertorio coreográfico habitual en fiestas de Saraos, Torneos, Minuetes, Vailes, y Contradanzas, las cuales se llaman lazos, información también valiosísima para reconstruir las danzas teatrales y de la que carecemos en los manuales de danza españoles ${ }^{62}$.

Una breve explicación sobre los signos de pausas en el compás nos remite de nuevo a Feuillet ${ }^{63}$ para finalizar con la música y coreografía de una entrada de Pabana ${ }^{64}$ seguida por las descripciones verbales de otras obras emblemáticas del repertorio español como la Pavana con 4 mudanzas, Gallarda, Españoleta, Villano o Cavallero, Jacara, Mariona, Torneo con castañuelas y entradas, Gaitta gallega y Canario ${ }^{65}$.

En España durante el siglo XVIII las danzas francesas más importantes eran el Minué y la Contradanza. Minguet en el prólogo de la Parte I de su libro da el siguiente consejo en relación a la práctica del Minué:

[...] incluso si no sabes más que las figuras coreográficas del minuet, es suficiente para tomar parte en cualquier sarao o fiesta, y bailar delante de cualquier caballero distinguido. Con respecto a las otras danzas -tales como el passapié, Bretaña, amable, etc.- si no las conoces no estas obligado a bailarlas; a menos de alguna contradanza, seguidillas, etc., las cuales son fáciles de aprender poniendo atención en las figuras coreográficas y movimientos realizados por la persona que empieza. Si no quieres bailarlas, puedes excusarte de forma educada, diciendo que estas cansado ${ }^{66}$.

Su coreografía no es fácil de aprender. Como Ferriol explica:

La danza más difícil y más exigente, y que demanda excepcional habilidad por la elegancia que debe reflejar el cuerpo, es el minuete. Si uno la conoce en profundidad, entonces puede aprender muy rápidamente y con gran perfección todo el repertorio ${ }^{67}$.

62. A este respecto consultar Ruíz MAYORdomo, M. ${ }^{a}$ J. y VAlCÁRCel, C. "Palabras en movimiento: Indicaciones coreográficas en tres manuscritos teatrales del siglo XVII (ms. 4.123, ms. $16291 \mathrm{y}$ ms. 16292) de la Biblioteca Nacional de Madrid» en Manuscrt. Cao, V (1993), pp. 67-101.

63. De la Mesure ou Cadence, pp. 87-92.

64. Se trata del único ejemplo musical consistente en un bajo que corresponde al esquema armónico de la Pabana española en el que se exponen algunos cifrados en los compases 13 y 14.

65. Pertenecientes a la Escuela por lo Vajo compuesta por Domingo González, según especifica el autor.

66. Minguet y Yrol, P. Op. cit., pt. I "Prólogo al lector", iv.

67. Ferriol y Boxeraus, B. Op. cit., tratado III, cap. 1, p. 181. 
La otra danza francesa importante en la corte española era la Contradanza ${ }^{68}$. Derivada de la Contredanse que a su vez fue importada del Reino Unido a Francia a finales del siglo XVII y principios del XVIII ${ }^{69}$. La popularidad de la Country dance en Inglaterra queda reflejada en las ocho ediciones del manual de Playford, editado en Londres entre 1651 y ca. $1728^{70}$.

De acuerdo con Ferriol, la Contradanza llegó a ser la danza más usada en las fiestas españolas, especialmente entre las jóvenes generaciones. En reconocimiento al uso internacional de la misma, Ferriol hace una lista de los términos de danza en cuatro lenguas diferentes: italiano, inglés, francés y catalán. Para cada término extranjero da su fonética y significado en español ${ }^{71}$. Una indicación adicional sobre su tremenda influencia es que la Contradanza podía incorporar elementos de otras danzas típicas. Por ejemplo, Ferriol da la melodía e instrucciones verbales para interpretar la Contradanza de el minuete del nardo y la Contradanza de el minuete de trompas ${ }^{72}$. Los títulos de otras Contradanzas indican un solapamiento con danzas españolas. Tal es el caso de La airosa malagueña, La catalana, y El suple seguidillas cuyas melodías y coreografías están contenidas en el tratado de Minguet ${ }^{73}$.

Hay una gran variedad posible en la interpretación de la Contradanza. Ferriol ofrece una discusión detallada en el capítulo final de su tratado. Aquí incluye las melodías y explicaciones coreográficas de numerosas contradanzas, cada una de las cuales pueden ser interpretadas de más de una manera ${ }^{74}$. Alguno de este material en este capítulo también aparece en la Parte III del tratado de Minguet ${ }^{75}$.

En contraste con la importancia de los pasos individuales o grupos de pasos (mudanzas) de las danzas españolas del siglo XVII, el principal énfasis en las Contradanzas del siglo XVIII son las figuras formadas por un grupo de bailarines. En la práctica, los bailarines podrían elegir sus propias secuencias de figuras. Minguet afirma que en bailes de máscaras en Barcelona y otros sitios, cada grupo de cuatro parejas interpreta una serie diferente de figuras durante una Contradanza ${ }^{76}$.

68. Consultar el siguiente artículo sobre la contradanza en nuestro país: Rico Osés, C. «La contradanza en España en el siglo XVIII: Ferriol y Boxeraus, Minguet e Yrol y los bailes públicos». Anuario Musical, enero-diciembre 2009, n. ${ }^{\circ}$ 64, pp. 191-214.

69. La combinación de elementos ingleses y franceses en la Contredanse temprana se discute en Guilcher, J. M. La Contredanse et les renouvellements de la danse française. Paris, 1969, pp. 13-85.

70. Playford, J. The English Dancing Master: or, Plaine and Easie Rules for the Dancing of Country Dances, with the Tune to Each Dance. London, 1651. Edición facsímil London, Margaret DeanSmith, 1957.

71. Ferriol y Boxeraus, B. Op. cit., tratado III, cap. 4, pp. 246 (38)-249 (41).

72. Ibid., tratado III, cap. 4, pp. 266 y 291 (81)-294 (84).

73. Minguet y Yrol, P. Op. cit., pt. II «Explicación de las 4 contradanzas que llaman airosas", lámina 26.

74. Solo para dos de las danzas Ferriol emplea notación coreográfica (tratado III, cap. 4 «El freno con clave francesa, y chorographía antigua», p. 270 (60); y «La gentil», pp. 279 (69)-280 (70).

75. Minguet y Yrol, P. Op. cit., pt. II, lámina 3-18, 26, y 57-58. Para todas ellas, excepto las 4 contradanzas airosas de la lámina 26, usa notación coreográfica.

76. Minguet Y Yrol, P. Op. cit., pt. III, p. 15 
La Contradanza mantuvo su importancia en la sociedad española durante el último tercio del siglo XVIII. Por ejemplo, en 1770 se organizó un baile de máscaras en el Coliseo de los Caños del Peral en Madrid, inspirado en aquellos de la Ópera de París. Sobrevive un manuscrito de algunas de las danzas que se bailaron allí en el citado año. Este documento consiste en las músicas y explicaciones verbales coreográficas de 24 Contradanzas nuevas ${ }^{77}$.

Las melodías llevan sobre determinados compases guarismos indicadores del cambio de las figuras e intervención de los bailarines, a su debido tiempo. Aunque algunas muestran acordes, no se sabe si serían ejecutadas por instrumentos de cuerda, clavecín o pequeño conjunto. Aunque tratándose de un gran baile de Carnaval, la agrupación más verosímil sería la orquesta.

Otras dos colecciones de Contradanzas de Madrid, que contienen melodías e instrucciones coreográficas, se conservan en la Biblioteca Nacional. Una consta de 12 danzas recopiladas por Marset y publicadas por Ibarra en $1775^{78}$. Siguen varias piezas a dos violines y bajo que parecen también música de contradanzas pero esta vez sin coreografía. Existen indicaciones dinámicas por compás (F. P.) que indican fraseo cada dos compases. También hay signos de articulación (ligaduras y staccato) en violín primero, segundo e incluso en el bajo y signos de ornamentos a la francesa en ambos violines. Aparece escrito al final: $A n^{\circ}$. Masco; lo Grabo.

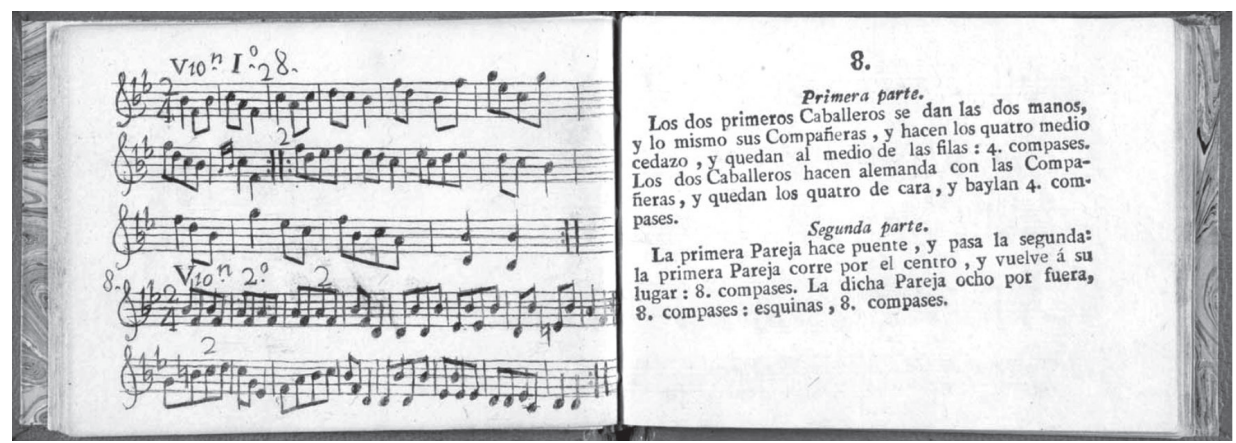

MARSET, J. Doce contradanzas nuevas abiertas, hechas para \{o por\} el principe nuestro señor, las que se baylaron \{o baylarán\} en este presente año de 1775: con su música de primero y segundo violín, y la explicación de figuras.

Madrid, 1775. E-Mn MC. ${ }^{a}$ 3602/34 (63).

77. Contrada\{nza\}s nuevas, que se han de baylar en el Amphitheatro de los Caños del Peral en los bayles en máscara del inmediato Carnaval de 1770. Con sus músicas, y explicación de figuras. E-Mah. Diversos, Mss sin numerar. Edición moderna a cargo de Álvarez SOLAR-QuinTES, N. "Contradanzas en el Teatro de los Caños del Peral, de Madrid». Anuario Musical, 1965, 20, pp. 86-103.

78. MARSET, J. Doce contradanzas nuevas abiertas, hechas para \{o por\} el príncipe nuestro señor, las que se baylaron \{o baylarán\} en este presente año de 1775: con su música de primero y segundo violín, y la explicación de figuras. Madrid, 1775. Signatura MC 3602/34. Una breve descripción de la copia conservada en la E-Mn es dada en AngLÉs, H. y SubIRÁ, J. Catálogo musical de la Biblioteca Nacional de Madrid. Barcelona: Instituto Español de Musicología, CSIC, vol. 3, 1951, p. 273. 
La otra es una colección anónima y sin fecha de 66 folios, todos manuscritos menos los cuatro últimos, donde se expone una explicación y método de cómo ejecutar los pasos y diferencias de Contradanzas francesas e inglesas ${ }^{79}$.

Bailes de máscaras al estilo francés también se dan en el este de España. De aquellos que se realizaron en Barcelona en 1768 hay una publicación de melodías y coreografía de varias Contradanzas ${ }^{80}$. De otros celebrados en la ciudad de Valencia hay una publicación editada por Monfort en 1769, cuya signatura es M. 857, que contiene descripciones coreográficas (sin música) de 32 Contradanzas algunas de ellas con el mismo título que las que aparecen en la fuente citada anteriormente ${ }^{81}$.

Se conserva un librito relacionado directamente con el documento anterior, pues informa sobre las normas a seguir para el mismo Baile de máscaras del año 1769 en la Casa Interina de Comedias de la ciudad de Valencia ${ }^{82}$. El objetivo era regular esta diversión y evitar incidentes, sin duda numerosos ya que la máscara favorece el anonimato, procurando la tranquilidad y el buen orden. Se exponen hasta 27 puntos en los que se tratan, entre otras, las siguientes cuestiones:

a) El precio de la entrada al baile, negándose el acceso a menores de edad.

b) La indumentaria adecuada haciendo una detallada descripción de los disfraces, tejidos, complementos y abalorios permitidos.

c) Accesibilidad al teatro sea en coche o a pie.

d) Regulación del servicio de guardarropía.

e) La organización de los bailes dentro del teatro mediante las figuras de dos Directores y dos Maestros de danzar.

f) Prohibición de fumar así como el uso de cualquier especie de arma.

g) Servicio de restauración y asistencia de Médico y Cirujano.

Importante información sobre la Contradanza se encuentra también en una obra satírica publicada en España durante la última década del siglo XVIII. Su autor, conocido bajo el pseudónimo de Don Preciso, ridiculiza a los caballeros y damas de moda -conocidos como currutacos, pirracas, y madamitas del nuevo cuño- que siguen modas francesas y formas de comportamiento ${ }^{83}$.

79. Varias contradanzas con sus músicas y explicación de todas figuras. E-Mn M. 918, en ANGLÉS y SuBIRÁ. Catálogo... Op. cit., 1946, vol. 1, pp. 431-34.

80. Rivas, R. y TORRENTS, S. Contradanzas que se han de baylar en el teatro de esta ciudad, en los bayles de máscaras del Carnaval de 1768. Con su música y explicación de figuras. Barcelona, sin fecha. Aparece en ANGLÉs y SuBIRÁ. Catálogo musical... Op. cit., vol. 3, pp. 272-273.

81. MONFORT, B. Contradanzas nuevas que se han de baylar en el teatro de la casa interina de comedias de la ciudad de Valencia en los bayles en máscara del inmediato Carnaval del año 1769. Valencia, 1769. Anglés y SuBIRÁ. Catálogo musical... Op. cit., vol. 3, p. 254.

82. Monfort, B. Politica, y Economia del bayle de Mascara en la casa interina de comedias de esta ciudad de Valencia para el Carnaval del año 1769. Valencia, 1769.

83. ZAMÁCOLA Y OZERÍN, J. A. de. Elementos de la ciencia contradanzaria, para que los currutacos, pirracas y madamitas del nuevo cuño puedan aprender por principios a baylar las contradanzas por sí solos, o con las sillas de su casa, $\& c$. $E c$. $\&$ c. Su autor don Preciso. Madrid, Imprenta de Fermín 


\section{LA PRESENCIA DEL MUNDO FRANCÉS EN LA DANZA URBANA}

En el campo de la danza aristocrática durante finales del siglo XVII y el XVIII, había una gran similitud entre las cortes de Europa occidental. Puede hablarse de un estilo internacional dentro del cual cada país exhibía sus propias predilecciones por ciertos tipos de danzas y sus propios rasgos interpretativos. Aunque los orígenes de algunas danzas son a menudo atribuidos a áreas geográficas específicas, las danzas circulaban ampliamente debido en parte a las relaciones familiares existentes entre las distintas casas reales.

Debido a su arrolladora presencia en los salones españoles del siglo XVIII el Minuet fue una de las danzas incluidas en la fiesta cómica conocida como la Momería que fue representada por 24 intérpretes en el Palacio de la Diputación de Barcelona para dar la bienvenida a Felipe V y la reina María Luisa en 1701. Esta fiesta también incluyó el Canario, Gran duque, Jácara, Paradeta, Torneo, y Turdión ${ }^{84}$. Los nombres de estas danzas ponen de manifiesto las influencias francesas e italianas y la permanencia de algunos caracteres hispánicos que se extiende a todo el arte creado para los primeros monarcas de la Casa de Borbón en España. Esta mezcla entre las permanencias y las aportaciones extranjeras ha sido analizada magistralmente por el gran historiador del arte en la corte española durante el siglo XVIII, Yves Bottineau ${ }^{85}$.

Además de bodas, entradas reales o cumpleaños de miembros de la familia real, uno de los acontecimientos de mayor calado social por su trascendencia política, y por tanto manifestado exteriormente mediante festejos, eran los natalicios, sobre todo de príncipes herederos. La embajada francesa en Madrid y la colonia francesa de Cádiz organizaron una fiesta con motivo del nacimiento del duque de Borgoña, primer hijo del delfín, en 1751.

Atrasada por el viaje de la corte a El Escorial, por las inclemencias del tiempo, por la inexperiencia de los oficiales y artesanos encargados de las obras, la fiesta se celebró por fin el 8 de febrero de 1752. Está profusamente descrita en una relación íntegramente publicada por el profesor Bottineau hace algunos años ${ }^{86}$.

\footnotetext{
Villalpando, 2. ${ }^{\mathrm{a}}$ edición, 1796. Se dispone de un ejemplar en E-Mn R.14656. Estos tipos de caballeros y damas eran conocidos como "petimetres" (del francés "petit maître»).

84. Festivas demonstraciones y magestuosos obsequios con que el muy ilustre y fidelíssimo consistorio de los deputados, y oydores del principado de Cataluña, celebró la dicha que llegó a lograr, con el deseado arribo, y feliz himeneo de sus católicos reyes d\{on\} Felipe IV de Aragón y V de Castilla, conde de Barcelona, Ec. y doña María Luisa Gabriela de Saboya. Barcelona, 1702. Consultar CAPMANY, A. «El baile y la danza». En CARreras y CANDi, F. (ed.). Folklore y costumbres de España, Barcelona, vol. 2, 1931, pp. 416-17.

85. Bottineau, Y. L'Art de Cour dans l'Espagne de Philippe V (1700-1746). "Bibliothèque de L'Ecole des Hautes Etudes Hispaniques", fasc. XXIX, Bordeaux, 1962.

86. Bottineau, Y. L'Art de Cour dans l'Espagne des lumières. Paris: éd. De Boccard, 1986, pp. 435-440. ("Détail de la fête que le comte de Vaulgrenant, ambassadeur extraordinaire du Roy, a donnée à Madrid le 8 février 1752 pour célébrer la naissance de Mgr. le duc de Bourgogne»).
} 
De la parte dedicada a las arquitecturas y decorados, él mismo ha hecho el resumen siguiente:

La fiesta reunía los placeres de la mesa, de la danza y de la música y el esplendor de los decorados efímeros, de las iluminaciones y de un fuego artificial. Este representaba un arco de triunfo de cuatro lienzos de unos 120 pies de altura colocado sobre un cuerpo rústico de 120 pies por 40. De este primer cuerpo almohadillado caían cascadas de agua en forma de capas: la del medio salía de un arco rebajado, y encima se veían dos ríos que figuraban el Tajo y el Sena mezclando sus aguas. Sobre este primer cuerpo se alzaba el arco de triunfo pintado en mármoles de distintos colores... Los dos lienzos principales se componían de dos grandes arcos debajo de la cornisa, cada uno sostenido por cuatro columnas aisladas. Las cifras del delfín y de la delfina, padres del nuevo príncipe, las figuras de la Esperanza y de la Felicidad, las de la Alegría y Flora daban al monumento su significado.

Otro detalle interesante: en la parte más alta del edificio, sobre un pedestal coronando el ático se veía "la cifra del Rey unida a la del Rey de España, sostenidas por la Amistad y por amores». Esta imagen y la de los dos ríos son las únicas alusiones a las relaciones entre ambas dinastías y ambos países. Arquitecturas efímeras, decorados, iluminaciones, fuegos artificiales se debían a la pericia y al talento de François Carlier, francés, arquitecto del rey de España ${ }^{87}$.

Después del refrigerio y una vez acabados los fuegos, los invitados pasaron al amplio salón de baile, enteramente transformado por decorados efímeros y empezó esta diversión. A las doce de la noche, se interrumpió para servir una cena tan copiosa como refinada, y luego se reanudó el baile hasta las siete de la mañana.

Las fiestas francesas celebradas en España con motivo de sucesos nacionales importantes no se limitan a las del embajador del Rey en Madrid. Se repiten en otros sitios, y particularmente en Cádiz donde vive y trabaja la colonia francesa más numerosa de la península ${ }^{88}$.

Ya que los consulados franceses dependían del secretario de Estado de Marina, es el titular de este departamento, Sr. Rouillé quien, en la noche del 13 de septiembre de 1751, envía al cónsul francés en Cádiz, Pierre Desvarennes, el despacho que anuncia el nacimiento del príncipe ${ }^{89}$.

El día 29 y el $1 .^{\circ}$ de octubre se reúnen en la casa consular las asambleas de la nación. Se eligen seis comisarios que en unión con el cónsul y los dos diputados en ejercicio, Pierre Bergez y François Lefer, organizarán las fiestas.

87. François Carlier (1707-1762), arquitecto del rey de España en 1739, era el hijo de René Carlier, también arquitecto del rey de España, llegado a Madrid en 1712 y fallecido en 1722.

88. Ozanam, D. "La colonie française de Cádiz au XVIII siècle». Mélanges de la Casa de Velázquez, 1968, t. IV, pp. 259-347.

89. Pierre Bigodet-Desvarennes (1683-1757), cónsul de Francia en Alicante (1714-1738), agente de la marina y del comercio de Francia en Madrid (1738-1748), cónsul en Cádiz (1748-1757). Se recibe la noticia en Cádiz el 27 de septiembre. 
Las celebraciones durarían tres días como de costumbre y tendrían dos centros: el tradicional de la plaza y el convento de San Francisco (que albergaba la capilla francesa de San Luis). Por fin el día 24 de noviembre, a la hora de ponerse el sol, una descarga de la artillería de los 34 barcos franceses fondeados en la bahía, dio la señal del inicio de las celebraciones ${ }^{90}$.

La mañana del 25 de noviembre se reservó para las ceremonias religiosas, en la iglesia del convento de San Francisco. Al principio de la noche, unos fuegos artificiales se dispararon cerca del convento de San Francisco que permaneció iluminado esta noche y las dos siguientes. Posteriormente el centro de las fiestas se desplazó hacia la plaza de San Antonio, la más grande de la ciudad y enteramente iluminada.

A un lado de la misma plaza se situaba la casa consular que Desvarennes había logrado ensanchar, flanqueándola de un cuerpo de edificio, un «anfiteatro", apoyado sobre la misma casa. Allí se hallaban reunidas más de cuatrocientas personas: el gobernador de Cádiz, el director general de marina, marqués de la Victoria, el teniente general de marina, Don Benito Spínola y la flor y nata de la sociedad gaditana. Sobre las seis de la tarde se empezó a servir el refresco, "es decir toda clase de aguas heladas, de limonada, de canela, de naranja, leche, etc., toda clase de sorbetes, luego confituras y chocolate». Dos horas después los asistentes se fueron a colocar en las ventanas y balcones de la casa o en el anfiteatro para ver los fuegos artificiales. Precedidos por el disparo de cohetes de todos colores, los fuegos artificiales, "los más hermosos jamás vistos en Cádiz", duraron unos tres cuartos de hora. Luego la sociedad volvió a los salones del cónsul donde abrieron el baile el marqués de la Victoria y la marquesa de Tirry, hija del teniente general Guillermo de Lacy. A las once de la noche se interrumpieron las danzas para tomar la cena: por falta de espacio esta se sirvió en dos mesas de treinta cubiertos y una de doce en las que se sucedieron tres veces los invitados. Después el baile se reanudó y duró hasta las cuatro de la madrugada.

La tercera noche, la del 27 de noviembre, fue igual de concurrida. Se repitieron, aun reforzadas, las iluminaciones. Sesenta músicos colocados dentro del templo tocaron juntos, siendo oídos de toda la plaza y aún más allá. Hasta los elementos se revelaron propicios ya que la noche fue muy quieta y sin viento, de tal manera que "la iluminación apareció con el máximo resplandor... y causó la admiración de todo Cádiz... Todos han sido encantados por este nuevo espectáculo y no paran de alabar a la nación por lo brillante de sus fiestas».

90. Arch. Nat. Paris, Marine, B7 379, 20 hojas. "Relation des réjouissances faites à Cádiz les 25, 26 et 27 novembre 751 par la nation française et son cónsul pour célébrer la naissance de Mgr le duc de Bourgogne». La carta de envío, del 6 de diciembre, está en el mismo legajo. 
Finalmente y como colofón, un documento más que describe este tipo de reuniones ${ }^{91}$. Se trata de la carta de Vauréal, obispo de Rennes, embajador de Francia en España (1741-1749), al duque de Richelieu, en Aranjuez, a 10 de junio de 1744 .

La fiesta comienza con un renfresco para las damas que están todas en una parte de la casa donde no hay ningún hombre. Viene un desfile de platos cargados de toda clase de aguas heladas y de confituras, y el desfile pasa de largo de las damas que son de rango d'oignon ${ }^{92} \ldots$ Cuando las damas han tenido de esto en abundancia, el desfile va a los hombres, que están al otro lado, y después se da un paquete de confituras para cada uno de los pajes o Gentileshombres que sirven a las damas. Cada uno lleva el suyo. Después del renfresco, un concierto o una comedia española, y es donde hay que morir no solo de aburrimiento, sino de desesperación o bien fuegos de artificio. Y al final una gran cena, que puede estar coronada por un baile sin máscaras donde se danza tanto como en las bodas. Cuando se pretende dar una fiesta, debe hacerse en tres ${ }^{93}$. En el primero se puede ofrecer un concierto italiano, en el segundo comedia española y en el tercero fuegos de artificio, y todos los días renfresco, cena y baile. Si Usted está tentado en ello... sería muy amable de enviar aquí dos meses antes todo lo necesario para disponer las decoraciones, los artificieros y aportar dos o tres mil libros de toda clase de confituras de París y flores ${ }^{94}$.

\section{FUENTES MANUSCRITAS}

Archivos de Danza de Derra de Moroda, Viena (DdM)

Beauchamp, P. Sarabande de M\{onsieu\}r de Beauchamp. Derra de Moroda Dance Archives, Mss DdM 797. Salzburg, Universität Salzburg, Institüt für Musikwissenschaft.

\section{Archivo del Palacio Real, Madrid (AGP)}

AGP. Casa de la Reina. Libro de Registros N. ${ }^{\circ} 175$. "Grefier, libro de informes 1718-1739".

AGP. Felipe V. Casa Real, leg. 292. Relación de los gastos y débitos a los criados y dependientes de la Cámara, Capilla, Casas y Caballerizas reales formadas de orden del Rey. AGP. Expedientes personales, C. ${ }^{a} 371$, dossier Fonton, n. ${ }^{\circ} 21$.

91. También puede consultarse J. Alenda y Mira, J. Relación de Solemnidades y Fiestas Públicas en España. Madrid, sucesores de Rivadenegra, 2 vols., 1903, pp. 339-527 (vol. I) y pp. 1-28 (vol. II) así como Torrione, M. (ed.). "Crónica Festiva de dos Reinados en la Gaceta de Madrid (1700-1759)». En: Revista de Musicología, 1999, XXII, 1, pp. 301-303. Sobre diferentes manifestaciones festivas en la España del siglo XVIII ver Torrione, M. (ed.). España Festejante. El s. XVIII. Málaga: Servicio de Publicaciones. Centro de Ediciones de la Diputación Provincial de Málaga, 2000.

92. Es decir, dispuestas según su rango protocolario.

93. Días.

94. Arch. Aff. Étr. Paris, Corr. pol. Espagne, vol. 481, fol. 69 v. ${ }^{\circ} 70$. 
AGP caja 12.963, N. ${ }^{\circ}$ 20. Expediente personal de Scío, Sebastián Christiani.

Archivo Nacional, París (Arch. Nat. Paris)

Relation des réjouissances faites à Cádiz les 25, 26 et 27 novembre 751 par la nation française et son cónsul pour célébrer la naissance de Mgr le duc de Bourgogne. Arch. Nat. Paris, Marine, B7 379.

Archivo Histórico Nacional, Madrid (E-Mah)

Contrada\{nzals nuevas, que se han de baylar en el Amphitheatro de los Caños del Peral en los bayles en máscara del inmediato Carnaval de 1770. Con sus músicas, y explicación de figuras. E-Mah. Diversos, Mss sin numerar.

E-Mah. Osuna, Cartas, leg. 388, n. ${ }^{\circ}$ 4. Christiano de Scío.

Archivos del Ministerio de Asuntos Exteriores, París (Arch. Aff. Étr. Paris)

Carta de la princesa de los Ursinos al marqués de Torcy, fechada el 19 de Noviembre de 1701. Archives du Ministère des Affaires Étr. Paris, Correspondance pol. Espagne, vol. 94 (Nov.- Dec., 1701), f. 125r-125v;

Carta de Vauréal, obispo de Rennes, embajador de Francia en España, al duque de Richelieu, en Aranjuez, a 10 de junio de 1744. Arch. Aff. Étr. Paris, Corr. pol. Espagne, vol. 481 , fol. 69 v. $^{\circ} 70$.

Biblioteca Nacional, Madrid (E-Mn)

E-MN BARBIERI Mss 14018/24 (9). Información sobre Maestros de Danza reales.

E-MN BARBIERI Mss 14020 (121). Antonio de Almenda.

E-MN BARBIERI Mss 14020 (122). Antonio de Almenda.

E-MN BARBIERI Mss 14030 (127). Manuel de Frías.

E-MN BARBIERI Mss 14030 (128). Manuel de Frías.

E-MN BARBieri Mss 14030 (130). Manuel de Frías.

E-Mn BARBIERI Mss 14030 (131 y 132). Manuel de Frías.

JAQUE, J. A. Libro de danzar. E-Mn Mss 18580/5 y E-Mn Barbieri Mss 14059/15.

Noveli, N. R. Choregraphia figurativa y demostrativa del Arte de Danzar, en la forma española. Compuesto por Don Nicolas Rodrigo Noveli, dedicado al prior del Consulado de S.n Sebastián que fuere electo el año tercero del próximo siglo. En Madrid año de 1708. Real Academia de Bellas Artes de San Fernando. Madrid. R-1220

RATIER, J. Observación I sobre el arte de la danza, de las muchas compuestas por don Joseph Ratier, antiguo académico en danza de las Academias Reales de Música de Francia, y maestro de ella en Cádiz, aprobadas por los más famosos maestros prácticos, y teóricos de la Europa, como se verá al fin de este discurso. Madrid, sin fecha. E-Mn Barbieri Mss 14059/16. Le sigue una copia manuscrita de Barbieri de la Aprobación de los más 
famosos maestros prácticos y teóricos de la Europa, sobre las Observaciones, principios $y$ reglas del arte de la danza. Sevilla, sin fecha. E-Mn M. 1258.

Biblioteca Pública Municipal, Oporto (P-Pm)

Libro de Diferentes Danzas quese estilan Bailar en saraos Politicos y en Palacios de Distintas cortes, para el señor D_n Manuel de Figueroa: Choregraphie o arte para saber danzar todas suertes de danzas por Choregraphie con caracteres, figuras $i$ señales demonstrativas. Traducido de su original por D_n Felix Kin... Maestro de Danza en esta Ciudad de Oportu. Oportu, 20 Henero de 1751. P-Pm Mss sin numerar.

\section{FUENTES IMPRESAS}

CAIRÓN, A. Compendio de las principales reglas del baile traducido del francés por A. Cairón y aumentado de una explicación exacta y método de ejecutar la mayor parte de los bailes conocidos en España, tanto antiguos como modernos. Madrid, Imprenta Repullés, 1820. E-Mn M 868.

Diccionario de la lengua castellana,... Compuesto por la Real Academia Española. 6 vols. Madrid, 1726, 1729, 1732, 1734, 1737 y 1739. Ed. facsímil Madrid, 1964.

Dufort, G. Trattato del Ballo Nobile. Felice Mosca, Napoli, 1728. Ed. facs. Gregg International publishers, 1972.

Durey de Joinville, J. B. Histoire du théâtre de l'Académie Royal de Musique en France, depuis son établissement jusqu'à présent. Paris, 1757. Ed. facsímil, Ginebra, 1972.

Esquivel Navarro, J. de. Discursos sobre el arte del dançado, y sus excelencias y primer origen, reprobando las acciones deshonestas. Compuesto por Juan de Esquivel Navarro, vezino y natural de la ciudad de Sevilla, discípulo de Antonio de Almenda, maestro de dançar de la majestad de el rey nuestro señor d\{on\}Phelipe Quarto el Grande, que Dios guarde. Dedicados a don Alonso Ortiz de Zúñiga Ponce de León y Sandoval, hijo primogénito del marqués de Valdenzinas, y sucesor en su casa, estado, y mayorazgos. Con licencia, impresos en Sevilla, por Juan Gómez de Blas. Año de 1642. Ed. Facsímil Valencia, Librerías "París-Valencia», 1992.

Ferriol y BoXeraus, B. Reglas útiles para los aficionados a danzar. Provechoso divertimiento de los que gustan tocar instrumentos. Y polýticas advertencias a todo género de personas. Adornado con varias láminas. Dedicado a la s\{acra\} m\{agestad\} del rey de las dos Sicilias, Ec. Su autor d\{on\} Bartholomé Ferriol y Boxeraus, único author en este idioma de todos los diferentes passos de danza francesa, con su brazeo correspondiente, chorografía, amable, contradanzas, Ec. Capoa: a costa de Joseph Testore, mercader de libros, a la calle Nueva. Año de MDCCXLV. Con licencia de los superiores. E-Mn M 860.

Feuillet, R. A. Chorégraphie ou l'art décrire la dance, par caractères, figures et signes démonstratifs, avec lequels on apprend facilement de soy-mêmes toutes sortes de dances. Paris, chez Michel Brunet, 1700. Ed. Facsímil New York, 1968.

MARSET, J. Doce contradanzas nuevas abiertas, hechas para \{o por\} el principe nuestro señor, las que se baylaron \{o baylarán\} en este presente año de 1775: con su música de primero y segundo violín, y la explicación de figuras. Madrid, 1775. E-Mn MC. ${ }^{a}$ $3602 / 34$. 
Minguet Y YROL, P. \{Parte I\} Arte de danzar a la francesa, adornado con cuarenta y tantas láminas, que enseñan el modo de hacer todos los passos de las danzas de corte, con todas sus reglas, $y$ de conducir los brazos en cada passo; y por chorographía demuestran cómo se deben escribir, y delinear otras: obra muy conveniente no solamente a la juventud, que quieren aprender el bien danzar, sino aun a las personas civiles, $y$ honestas, a quien les enseña las reglas para bien andar, saludar, y hacer las cortesías, que convienen en qualquier suerte de personas. Corregido en esta tercera impressión por su autor Pablo Minguet e Yrol. Madrid, 1758. E-Mn R. 14649.

Minguet Y YROL, P. \{Parte II\} El noble arte de danzar a la francesa, y española; adornado con LX láminas finas, que enseñan el modo de hacer todos los passos de las danzas de corte, con sus reglas, y de conducir los brazos, en cada passo; y por chorographía demuestran cómo se deben escribir otras. Madrid, sin fecha. E-Mn R. 14607.

Minguet y YROL, P. \{Parte III\} Quadernillo curioso, de veinte contradanzas nuevas, escritas de todas quantas maneras se han inventado hasta aora; tienen la música muy alegre, y con su baxo: compuestas por Pablo Minguet. Los bayles más divertidos en la juventud, son las contradanzas, de quienes he querido explicar en éste algunas; mas como hay distintos gustos en baylarlas, las he puesto de quatro modos, que son largas, redondas, quadradas, $y$ de dos pares, para que los aficionados elijan el suyo en las máscaras, y en otras funciones. Trae quarenta (sic) diferencias muy curiosas, que sabiendo algunas de memoria, pueden baylar qualquiera contradanza, siguiendo el ayre, y compás de la música que tañen; sirven para baylar las seguidillas en los dichos 4 modos. Madrid, sin fecha.

Minguet Y YRol, P. \{Parte IV\} Breve tratado de los passos del danzar a la española, que oy se estilan en las seguidillas, fandango, y otros tañidos. También sirven en las danzas italianas, francesas, e inglesas, siguiendo el compás de la música, y las figuras de sus bayles. Corregido en esta segunda impressión por su autor Pablo Minguet. Madrid, 1764. E-Mn R.14607 y E-Mn Barbieri R. 14649.

MONFORT, B. Contradanzas nuevas que se han de baylar en el teatro de la casa interina de comedias de la ciudad de Valencia en los bayles en máscara del inmediato Carnaval del año 1769. Valencia, 1769.

Monfort, B. Politica, y Economia del bayle de Mascara en la casa interina de comedias de esta ciudad de Valencia para el Carnaval del año 1769. Valencia, 1769.

Playford, J. The English Dancing Master: or, Plaine and Easie Rules for the Dancing of Country Dances, with the Tune to Each Dance. London, 1651. Edición facsímil London, Margaret Dean-Smith, 1957.

RAmeAu, P. Abbrégé de la nouvelle méthode dans l'art de écrire ou de tracer toutes sortes de danses de ville. Paris, ca. 1725. Ed. facsímil Westmead, 1972.

RAMEAU, P. Le maître à danser. Qui enseigne la manière de faire tous les différens pas de danse dans toute la regularité de l'art, E de conduire les bras à chaque pas. Paris, 1725. Ed. facsímil New York, 1967.

RIVAS, R. y TORRENTS, S. Contradanzas que se han de baylar en el teatro de esta ciudad, en los bayles de máscaras del Carnaval de 1768. Con su música y explicación de figuras. Barcelona, sin fecha.

ROXO DE FloRES, F. Tratado de recreación instructiva sobre la Danza: su invención y diferencias. Madrid, Imprenta Real, 1793.

Varias contradanzas con sus músicas y explicación de todas figuras. E-Mn M. 918.

ZAMÁCOla y OzERín, J. A. de. Elementos de la ciencia contradanzaria, para que los currutacos, pirracas y madamitas del nuevo cuño puedan aprender por principios a baylar las 
contradanzas por sí solos, o con las sillas de su casa, Ec. $E c$. Ec. Su autor don Preciso. Madrid, Imprenta de Fermín Villalpando, 2. ${ }^{a}$ edición, 1796. E-Mn R.14656.

\section{BIBLIOGRAFÍA}

ALENDA Y MiRA, J. Relación de solemnidades y fiestas públicas en España. Madrid: sucesores de Rivadenegra, 2 vols., 1903.

Álvarez Solar-Quintés, N. "Contradanzas en el Teatro de los Caños del Peral, de Madrid». Anuario Musical, 1965, 20, pp. 86-103.

Anglés, H. y SubirÁ, J. Catálogo musical de la Biblioteca Nacional de Madrid. Barcelona: Instituto Español de Musicología, CSIC, 3 vols., 1946, 1949 y 1951.

Antoine, M. Henry Desmaret (1661-1741). Biographie critique. Paris: Éditions A. et J. Picard, 1965.

BAGÜES, J. «La música y la danza en los proyectos pedagógicos de la Real Sociedad Bascongada de los Amigos del País». Recerca Musicológica, 1988, VIII, pp. 177-131.

Benoit, M. "Les musiciens français de Marie-Louise d'Orléans, Reine d'Espagne». Revue Musicale, 1953-1954, 226, pp. 48-60.

Bottineau, Y. L'art de cour dans l'Espagne de Philippe V (1700-1746). Bordeaux, «Bibliothèque de L'Ecole des Hautes Etudes Hispaniques", fasc. XXIX, 1962.

Bottineau, Y. L'art de cour dans l'Espagne des lumières. Paris: Ed. De Boccard, 1986.

CAMPÓo SCHELOTTO, D. «Danza y Educación nobiliaria en el siglo XVIII: El método de la Escuela de Baile en el Real Seminario de Nobles de Madrid». Revista del Departamento de Historia del Arte y Música de la Universidad del País Vasco, 2015, n. ${ }^{\circ}$ 5, pp. 157-173.

Capmany, A. "El baile y la danza». En Carreras y Candi, F. (ed.). Folklore y costumbres de España, Barcelona, vol. 2, 1931, pp. 167-418.

CARreras, J. J. "L'Espagne et les influences européennes: la musique française à la cour d'Espagne (1679-1714)». Échanges Musicaux franco-espagnols XVIIe-XVIIIe siècles. Actes des Rencontres de Villecroze, réunis par François Lesure, Académie Musicale de Villecroze, 15 au 17 octobre 2000, pp. 61-82.

Derra De Moroda, F. «Chorégraphie, the Dance Notation of the Eighteen century; Beauchamp or Feuillet?». The Book Collector, 1967, 16, pl. 1, p. 464.

Ellis LitTLE, M. «The Contribution of Dance Steps to Musical Analysis and Performance: 'La Bourgogne'». Journal of the American Musicological Society, 1975, 28, pp. 112-30.

EsSES, M. Dance and Instrumental 'Diferencias' in Spain during the 17th and early $18^{\text {th }}$ Centuries. New York: Pendragon Press Stuyvesant, 3 vols., 1992.

ESSES, M. «New Information Concerning some Music Research Libraries in Spain». Fontes artis musicae, 1979, 26, pp. 189-191.

GuILCHER, J. M. La contredanse et les renouvellements de la danse française. Paris, 1969.

KANY, C. E. Life and Manners in Madrid 1750-1800. Berkeley, 1932.

LANCElot, F. La Belle Dance. Catalogue raisonné fait en l'an 1995. París: van Dieren éditeur, 1996.

MARTínEZ DEL FRESNO, B. «Intercambios culturales entre Francia y España a través de la danza: identidad, recepción y circulación en los siglos XVIII y XIX». En MARTínEZ DEL Fresno, Beatriz (ed.). Coreografiar la historia europea: cuerpo, politica, identidad y género en la danza. Oviedo: Universidad de Oviedo, 2011.

Mera, G. "La danza, el baile, los saraos, la danza escénica y los bailes populares. Notas y precisiones sobre su estado en la España ilustrada». En Lolo, Begoña (Coord). Teatro 
y música en España: los géneros breves en la segunda mitad del siglo XVIII. CSIC y Universidad Autónoma de Madrid, 2008.

Mera, G. "Los ilustrados y la danza a principios del siglo XIX: polémicas sobre la construcción de una identidad nacional frente al modelo francés. En MARTínez DEL FrESNO, Beatriz (ed.). Coreografiar Europa, Cuerpo, Política, Identidad y Género en la danza. Ediciones de la Universidad de Oviedo, 2013, pp. 173-199.

Ozanam, D. «La colonie française de Cádiz au XVIII siècle...». Mélanges de la Casa de Velázquez, 1968, t. IV, pp. 259-347.

RAVENTÓS I FREIXA, J. "La danza francesa en Barcelona durante el siglo XVIII: recepción y transformación". TRANS 2 (1996). Identidad étnica en el contexto de la globalización y la diversificación de prácticas musicales en países iberoamericanos. II Encuentro Iberoamericano de etnomusicología, Barcelona. Del 30 de junio al 2 de julio de 1995.

RICo OsÉs, C. «De las ceremonias de los bailes». Bulletin hispanique, 2012, 114-2, pp. 645669.

RICO OsÉs, C. «La contradanza en España en el siglo XVIII: Ferriol y Boxeraus, Minguet e Yrol y los bailes públicos». Anuario Musical, enero-diciembre, n 64, 2009, pp. 191214.

RUíz MAYORDomo, M. J. «Danza impresa durante el siglo XVIII en España: ¿inversión o consumo? En Lolo, Begoña y Gosálvez, José Carlos (eds.). Imprenta y edición musical en España (ss. XVIII-XX). Madrid, Universidad Autónoma de Madrid: 2012, pp. 131-144.

SALDONI Y REMENDO, B. Diccionario biográfico-bibliográfico de efemérides de músicos españoles. Madrid: Imprenta de Antonio Pérez Dubrull, 1868-1881. Ed. facsímil por Jacinto Torres. Madrid, INAEM, Centro de Documentación Musical, 4 vols., 1986.

SANHUESA FOnSECA M. "Carlos II y las "Dancerías de la Reyna": violones y danza en las postrimerías de la casa de Austria». Revista de Musicología, 1997, XX, 1, pp. 261-276.

SiemENS HeRnANDEZ, L. "Sebastián Christiani de Scío y su familia: contribución a los maestros de danzar en la España del siglo XVIII». Revista de Musicología, 1997, XX, 1, pp. 323-329.

SIMÓn DíAz, J. Historia del Colegio Imperial de Madrid. 2 vols. Madrid, 1952 y 1959.

STEIN, L. K. Songs of Mortals, Dialogues of the Gods. Music and Theatre in SeventeenthCentury Spain. Oxford: Clarendon Press, 1993.

Subirá, J. «Necrologías musicales madrileñas (1611-1808)». Anuario Musical, 1958, XIII, pp. 201-23.

Torrione, M. (ed.). "Crónica Festiva de dos Reinados en la Gaceta de Madrid (1700-1759)». Revista de Musicología, 1999, XXII, 1, pp. 301-303.

Torrione, M. (ed.). España Festejante. El s. XVIII. Málaga: Servicio de Publicaciones. Centro de Ediciones de la Diputación Provincial de Málaga, 2000. 